\title{
COVID-19, Moral Conflict, Distress, and Dying Alone
}

\author{
Lisa K. Anderson-Shaw $(D)$ Fred A. Zar
}

Received: 3 May 2020 / Accepted: 26 August 2020

(C) Journal of Bioethical Inquiry Pty Ltd. 2020

\begin{abstract}
COVID-19 has truly affected most of the world over the past many months, perhaps more than any other event in recent history. In the wake of this pandemic are patients, family members, and various types of care providers, all of whom share different levels of moral distress. Moral conflict occurs in disputes when individuals or groups have differences over, or are unable to translate to each other, deeply held beliefs, knowledge, and values. Such conflicts can seriously affect healthcare providers and cause distress during disastrous situations such as pandemics when medical and human resources are stretched to the point of exhaustion. In the current pandemic, most hospitals and healthcare institutions in the United States have not allowed visitors to come to the hospitals to see their family or loved ones, even when the patient is dying. The moral conflict and moral distress (being constrained from doing what you think is right) among care providers when they see their patients dying alone can be unbearable and lead to ongoing grief and sadness. This paper will explore the concepts of moral distress and conflict among hospital staff and how a system-wide
\end{abstract}

L. K. Anderson-Shaw ( $\bowtie)$

Department of Medical Education, University of Illinois College of Medicine, 1853 Polk Street (m/c 785), Chicago, IL 60612, USA e-mail: 1kas@uic.edu

F. A. Zar

University of Illinois College of Medicine, 840 South Wood Street \#440, Chicago, IL 60612, USA

e-mail: Fazar@uic.edu provider wellness programme can make a difference in healing and health.

Keywords COVID-19 - Moral distress · Moral conflict . End of life

\section{Introduction}

COVID-19 has affected most of the world over the past many months, perhaps more than any other event in recent history. Left in the wake of this pandemic are the patients, family members, and various types of healthcare workers (HCWs), all of whom share different levels of moral conflict.

Moral conflict occurs in disputes when individuals or groups have differences over-or are unable to translate to each other-deeply held beliefs, knowledge, and values, including those used to make judgements about the experiences and perspectives of others (Cole 2014). Such conflicts can seriously affect healthcare providers during disastrous situations such as pandemics when medical and human resources can be stretched to the point of exhaustion.

Because the virus is easily spread by contact with respiratory secretions, many hospitals and healthcare institutions in the United States have not allowed visitors to come to the hospitals to see their family or loved ones. This includes when a patient is actively dying of their illness. Thus, most patients are dying alone in hospital rooms with only strangers at the bedside during their last breaths. 
The moral conflict among care providers when they see their patients dying alone can be unbearable and lead to ongoing grief and sadness. This paper will explore the concepts of moral conflict and distress among hospital staff and how a system-wide provider wellness programme can make a difference in healing and health.

\section{Moral Distress and Moral Conflict}

Since 1984 much has been written in the nursing literature about the concept of moral distress and conflict. Jameton defined moral distress in his 1984 book, Nursing Practice: The Ethical Issues as "(a) the psychological distress of (b) being in a situation in which one is constrained from acting (c) on what one knows to be right" (Jameton 1984, 6). Since that time, much interest and attention from researchers and healthcare organizations regarding moral distress and moral conflict among all healthcare providers (including physicians, social workers, chaplains, and therapists) has ensued.

Moral conflict was described by Jean-Paul Sartre in 1957 as a conflict of obligations - "being torn between two kinds of morality: one of limited scope but certain efficacy ... the other of much wider scope but uncertain efficacy" (quoted in McConnell 2018, 1). The terms moral distress and moral conflict are very similar in nature and both describe feelings of conflict, distress, and sadness when applied to situations where one is unable to take the right action according to one's belief system, professional standards, religious beliefs, or other forms of personal conviction.

Moral distress and moral conflict in the clinical setting may not always cause extreme feelings of anxiety, frustration, or sadness in a clinician. Clinical situations in both hospitals and outpatient facilities may cause provider concern, for example, when treatment options are limited for a specific patient, yet not result in serious distress or conflict. However, serious moral distress and conflict in clinical situations may arise frequently in disaster and/or pandemic health situations. It occurs when the clinical decisions must be made for patient care based on survival data and scarce resources and providers must make decisions about allocation of scarce resources such as ventilators and dialysis.

In an epidemic situation or large-scale disaster, medical and human resources may be stretched to the point of exhaustion. Appropriate planning must incorporate plans of action that minimize public health morbidity and mortality while maximizing the appropriate use of medical and human healthcare resources. (Lin and Anderson-Shaw 2009, 215)

Because resource-allocation decisions are forced on clinicians in many hospitals throughout the world, the current COVID-19 pandemic will certainly result in high rates of much moral distress and conflict for those HCWs taking care of the sickest of patients.

\section{COVID-19 in the United States}

The COVID-19 pandemic began in China in December 2019 with the virus spreading rapidly through Europe and surrounding countries. The first case reported in the United States was on January 19, 2020, in the state of Washington (Holshue et al. 2020). The patient had returned from a trip to Wuhan on January 15 . The virus quickly spread throughout the entire United States. New York City by far has had the greatest number of deaths of any American city with over 23,000 attributed to the coronavirus (as at July 2020) (CDC 2020a).

New York City is the most populated city in the United States with over 8.3 million people living in its three hundred square miles. It is because of the density of this large population that the COVID-19 virus spread so quickly to so many people. The number of patients presenting to emergency departments rapidly overwhelmed New York City hospitals (Katz and Sanger-Katz 2020). Many other hospitals and medical centres in other large cities began to experience a surge of patients being tested and treated for the virus. It didn't take long for hospitals to have shortages of needed personal protective equipment as well as physicians, nurses, and hospital beds that could accommodate patients with COVID-19.

The April 17, 2020, CDC Morbidity and Mortality Weekly Report noted that the United States has approximately eighteen million HCWs working in healthcare settings who have "potential for direct or indirect exposure to patients or infectious materials" (CDC 2020b). This report also identified that over nine thousand HCWs had confirmed cases of COVID-19, noting that some cases may have been community acquired. The stress of COVID-19 on HCWs is not only in the clinical setting (donning PPE, risk of acquiring the virus, taking care of very sick and dying patients every day) but also 
in the home setting with many COVID-19 infected $\mathrm{HCW}$ living in separate spaces in their homes so as not to infect spouses, children, and other family members living with them.

\section{Allocation of Scarce Healthcare Resources}

As COVID-19 patients began to flood hospital emergency rooms and ICU beds, the concern among medical and nursing staff, ethicists, and hospital directors was how to make difficult allocation decisions should there be a shortage of some critical resources. Committees began working on recommendations for fair and ethical guidelines should resources like ventilators, dialysis machines, catheters, and blood products become scarce and a need for rationing occur. In the United States the production of ventilators in anticipation of this critical situation ramped up to the point that automobile manufacturing plants began to assemble and produce them.

Triage guidelines were needed to assist in a consistent and ethical allocation process, much like military and disaster triage processes. Such disaster triage plans look to save the most lives as well as look at which patients would likely survive long term. Triage committees are the most common way medical institutions set up resource allocation triage plans. The triage guidelines take into account the patients' clinical conditions including co-morbidities using specific assessment tools to assess mortality risk and general survival data. Only under the direst of circumstances are triage guidelines used, and allocation decisions are a cause of moral conflict for those involved. For many providers, such decisions have never been asked of them before.

\section{Provider Stress}

The stress on healthcare personnel caring for COVID19 patients may also take a personal toll that includes depression, anxiety, exhaustion, moral distress, and moral conflict. An early study of mental health in providers caring for COVID-19 patients assessed more than 1200 healthcare workers from China in late January 2019. Standardized tests were used to assess for depression, anxiety, insomnia, and psychological distress. The study outcomes showed higher incidence of all four test indicators with providers caring for COVID-19 patients as compared to providers who were not taking care of COVID-19 patients. The study noted that work-related factors included the psychological distress of providing front-line care to COVID-19 patients, shortages of PPE and ongoing fear of exposure, shortages of resources like ventilators in hospitals caring for large numbers of infected patients, and the unfamiliar care tasks of taking care of infected patients (Ayanian 2020).

The stress of caring for patients with communicable diseases is often related to one's moral obligation to do so. Zuger and Miles discussed this in 1987 in relation to the AIDS pandemic, noting that the professional duty to treat patients with human immunodeficiency virus "is a virtuous act, which meets both patients' and society's health needs and affirms the moral mission of health care" (Zuger and Miles 1987, I1). Similarly, Minkoff and Ecker wrote about this obligation in relation to providing care to patients with AIDS and Ebola, noting that it can be seen as an occupational risk arising from the ethical obligation to provide such care.

In order to do so the implicit contract between society and its physicians will be considered, as will many of the arguments that are redolent of those that were litigated 30 years ago when acquired immune deficiency syndrome (AIDS) was raising public fears to similar levels, and some physicians were publically proclaiming their unwillingness to render care to those individuals. (Minkoff and Ecker 2015, I11)

In a 2009 article, Robert Maunder described the psychological toll of severe acute respiratory syndrome (SARS) on healthcare providers during the 2002-2003 pandemic. He likened the term "catastrophe" to the "psychological cost of an infection" due to systems that cause abrupt discontinuous change (Maunder 2009). He also suggested that the stress for healthcare workers taking care of large numbers of patients who have infectious disease processes during a crisis or pandemic is very different from the stress of taking care of patients when not in a crisis or disaster situation. Because we knew more about stress to healthcare workers from the SARS experience, Maunder hypothesized that institutions and health systems would learn from the past and prepare for the next disaster in advance with wellthought-out guidelines for assisting the emotional and psychological needs of care providers when the next pandemic/disaster occurs. 
Perhaps looking back on the current COVID-19 pandemic as we move toward a post-peak-COVID-19 world we must plan ongoing and long-term mental health and wellness maintenance programmes for our healthcare workers. From March 2020, healthcare institutions in the United States began mobilizing resources to care for pandemic patients, as well as organizing health and wellness resources for their clinical and supportive care staff, especially in larger cities with large medical centres. Such efforts included providing meals for staff, housing for staff who did not wish to expose family members to COVID-19, online links to resources for dealing with stress and anxiety, setting up resource information hotlines, and bringing in psychiatrist and therapists for telemedicine appointments for any staff member who need such support. Telemedicine for triage, virtual clinic appointments, and healthcare monitoring is prevalent in most large medical systems in some form or other. (Hollander and Carr 2020) This is especially important for front-line healthcare providers who are in need of help dealing with their stressful work and life environment but are not able to see a therapist in person due to COVID-19 stay-at-home orders.

\section{Dying Alone}

Hospitals and emergency departments have enforced restrictions on all visitors. Long-term care facilities have similar restrictions, and the people who live in these facilities are not allowed to leave the facility. When patients need their loved ones most-when they are scared, critically ill, or dying-loved ones are not allowed to be with them.

"The fear of dying alone is nearly universal — a fact of which anyone who's taken care of critically ill patient is acutely aware" (Wakam et al. 2020, II 3). Even though these strict visitor guidelines appear justified, the emotional toll on providers and family members is great. Clinical staff spend much of their time speaking with family members on the phone providing frequent clinical updates to family members.

Non-critical patients may be able to use their cell phones and tablets to keep in regular contact with loved ones, but patients in the ICU who are sedated on a ventilator are not able to communicate with family by phone. In addition, patients in the hospital for other diseases such as cancer or cardiac disease are also dying without family at the bedside. Chaplains, social workers, and many other human resources are used to keep in touch with seriously ill patients' family members and may even be present when a patient dies so the patient does not die alone.

\section{From the Field-Conflict and Distress in the Next Generation of Physicians: Residents in Training}

Perhaps the most vulnerable physicians are those in their initial years of training in thousands of residency programmes throughout the United States. They have only been physicians for a few years and thus are the least experienced physicians in the work force yet are often on the front lines of seeing patients.

\section{Selfless Versus Self and our Own Mortality}

Prior to entering residency, medical students for centuries have recited the Hippocratic oath when they receive their medical degrees. In it there are two relevant proclamations: "I will use treatment to help the sick according to my ability ..." and "Into whatsoever houses I enter, I will enter to help the sick ...". Oaths of service, such as the Hippocratic oath, have given way in modern times to various new statements or pledges of obligation to provide healthcare to those in need. Resident physicians in training are well aware that infectious diseases are the only illnesses transmissible from our patients to HCWs, and only a few of these diseases are as easily communicable as COVID-19. The personal obligation of service to those in need, for many young physicians in training, may conflict with their fear of illness, fear of passing on illness to their family, and fear of dying from a disease that has no cure at the present time (Murphy 2020; Gallagher and Schleyer 2020).

\section{Protective Personal Equipment: Available Versus Valuable}

As new infectious disease pandemics evolve, so does the science on their transmissibility and, based on this, the recommendations for preventing spread to the community in general and HCWs specifically. It was recognized early on that respiratory droplets spread COVID-19, and HCWs seeing patients with known or suspected infection were advised to wear masks. Initially, just regular surgical masks were recommended, but this was supervened by 
recommendations for more highly effective (N95) masks when seeing some patients, after which they were recommended when seeing all patients. In addition, as the pandemic progressed, many institutions have moved to masking all HCWs as well as all patients. Although the increased use of protective equipment may be comforting for $\mathrm{HCWs}$, it also creates concerns in their minds with the question "If this is the best thing to do now, why weren't we doing it before?" The answer to this is twofold. Firstly, the science related to transmission has evolved. What is harder to process is that-secondly - appropriate protective equipment was not available even though it may have been indicated.

\section{Hazards at Home}

Fear of self-harm is often outpaced by fear of bringing COVID-19 home to loved ones, especially if they have underlying diseases that place them at risk for serious infection or death. This has led some HCWs to live in isolation at home (separate bedrooms or in the basement) or to move in to hotels completely away from families. This loss of companionship can add to or create depression and deplete a HCWs access to wellness activities.

\section{Staying in Touch Without Touching}

Residents commonly function as a family, sharing their experiences, triumphs, and challenges, knowing they will have an empathetic ear from colleagues experiencing the same challenges. It is quite common for them to share meals when at the hospital or to enjoy each other's company at restaurants, homes, or community events. Social distancing has brought these activities to a screeching halt, creating a loss of the camaraderie that is a normally a vital pillar of wellness during residency training.

\section{COVID Casualties Among Resident Physicians}

The American Medical Association recently updated their Code of Medical Ethics to provide guidance in pandemic situations. Opinion 8.3 of this code states

Because of their commitment to care for the sick and injured, individual physicians have an obligation to provide urgent medical care during disasters. This obligation holds even in the face of greater than usual risks to physicians' own safety, health, or life. (AMA 2020, \[3)

For some physicians-in-training, this code may be daunting, given that many young physicians taking care of infected patients in intensive care units may only have been physicians for less than a year when the pandemic started. The stress can be great when the burden of care for COVID-19 patients leads to exhaustion and moral conflict and distress.

Resident physicians, as all healthcare workers do from time to time, use coping mechanisms to get through stressful times. Denial is one common coping mechanism that allows for the adjustment to distressing situations (Mayo Clinic 2020).

Some form of denial may be helpful in times where the risk of morbidity and mortality might affect the ability to objectively carry out their commitment to care for patients. Even so, the clinical pressures of taking care of patients who are seriously ill and dying day after day can take a serious toll on front-line providers. The stress of taking care of COVID-19 patients and seeing coworkers die from the virus can even lead to suicide. The medical director of the emergency department at New York Presbyterian Allen Hospital died on April 24, 2020. She acquired COVID-19 at work, which she survived, only to psychologically succumb to the pandemic by taking her own life (Watkins et al. 2020). The long shifts in the emergency department, coupled with the recurrent times she held the hands of those dying alone, brought her to this brink, and residents wonder how close they are to this edge with every COVIDinfected death they see or hear of.

\section{Conclusion}

Much has already been learned about COVID-19 both scientifically and socially. We are realizing that the emotional toll for healthcare workers who have battled on the front lines is multifactorial and will last a lifetime. The more we can learn about the genesis of their moral conflicts and distress, the better equipped we will be to assist them now and in the future. We must also prepare for the next pandemic, because if we have learned anything from the last several centuries, there surely will be one. 


\section{References}

American Medical Association. 2020. AMA code of medical ethics: Guidance in a pandemic. Updated April 14, 2020. https://www.ama-assn.org/delivering-care/ethics/ama-codemedical-ethics-guidance-pandemic. Accessed June 7, 2020.

Ayanian, J. 2020. Mental health needs of health care workers providing front-line COVID-19 care. JAMA Health Forum, April 1. https://jamanetwork.com/channels/healthforum/fullarticle/2764228

CDC (Centers for Disease Control and Prevention). 2020a. Coronavirus disease 2019 (COVID-19). Cases, data, \& surveillance. Cases in the US. https://www.cdc. gov/coronavirus/2019-ncov/cases-updates/cases-in-us.html. Accessed April 27, 2020.

CDC (Centers for Disease Control and Prevention). 2020b. Characteristics of health care personnel with COVID-19United States, February 12-April 9. Morbidity and Mortality Weekly Report 69(15): 477-481. https://www.cdc. gov/mmwr/volumes $/ 69 / \mathrm{wr} / \mathrm{mm} 6915 \mathrm{e} 6 . \mathrm{htm}$ ?s_cid=mm6915 e6_w. .

Cole, K. 2014. Moral conflict. Key concepts in intercultural dialogue, number 33. https://centerforinterculturaldialogue.files. wordpress.com/2014/09/key-concept-moral-conflict.pdf. Accessed May 5, 2020.

Gallagher, T., and A. Schleyer. 2020. We signed up for this!Student and trainee responses to the covid-19 pandemic. The New England Journal of Medicine 382(25): e96

Hollander, J., and B. Carr. (2020) Virtually perfect? Telemedicine for Covid-19. The New England Journal of Medicine. 382(18):1679-1681.

Holshue, M., C. DeBolt, S. Lindquist, et al. 2020. First case of 2019 novel coronavirus in the United States. The New England Journal of Medicine 382(10): 929-936.

Jameton, A. 1984. Nursing practice: The ethical issues. Englewood Cliffs: Prentice Hall.

Katz, J., and M. Sanger-Katz. 2020. N.Y.C. deaths reach 6 times the normal level, far more than coronavirus count suggests. The New York Times, April 27. https://www.nytimes. com/interactive/2020/04/27/upshot/coronavirus-deaths-newyork-city.html. Accessed April 29, 2020.
Lin, J., and L. Anderson-Shaw. 2009. Rationing of resources: Ethical issues in disasters and epidemic situations. Prehospital and Disaster Medicine 24(3): 215-221.

Maunder, R. 2009.Was SARS a mental health catastrophe? General Hospital Psychiatry 31(4): 316-317.

Mayo Clinic. 2020. Denial: When it helps, when it hurts. https://www.mayoclinic.org/healthy-lifestyle/adulthealth/in-depth/denial/art-20047926. Accessed June 7, 2020.

McConnell, T. 2018. Moral Dilemmas. In The Stanford encyclopedia of philosophy, Fall 2018 ed., edited by E. Zalta. https://plato.stanford.edu/entries/moral-dilemmas/. Accessed April 25, 2020.

Minkoff, H., and J. Esker. 2015. Physicians' obligations to patients infected with Ebola: Echoes of acquired immune deficiency syndrome. American Journal of Obstetrics and Gynecology 212(4): 456e1-4.

Murphy, B. 2020. Residency in a pandemic: How COVID-19 is affecting trainees. American Medical Association, April 1. h t t p s : / / w w w . a m a - a s s n . org/residen t sstudents/residency/residency-pandemic-how-covid-19affecting-trainees. Accessed June 7, 2020.

Verbeek, J.H., C. Mischke, and J.H. Ruotsalainen, et al. 2016. Personal protective equipment for preventing highly infectious diseases due to exposure to contaminated body fluids in healthcare staff. Cochrane Database of Systematic Reviews, issue 4: CD011621.

Wakam, G., J. Montgomery, B. Biesterveld, and C. Brown. 2020. Not dying alone - modern compassionate care in the Covid19 pandemic. The New England Journal of Medicine 382: e88.

Watkins, A., M. Rothfeld, W. Rashbaum, and B. Rosenthal. 2020. Top E.R. doctor who treated virus patients dies by suicide. The New York Times, April 27. https://www.nytimes. com/2020/04/27/nyregion/new-york-city-doctor-suicidecoronavirus.html. Accessed June 7, 2020.

Zuger, A., and S. Miles. 1987. Physicians, AIDS, and occupational risk: Historic traditions and ethical obligations. JAMA 258(14):1924-1928.

Publisher's Note Springer Nature remains neutral with regard to jurisdictional claims in published maps and institutional affiliations. 